\title{
Radioxenon Releases from A Nuclear Power Plant: Stack Data and Atmospheric Measurements
}

\author{
A. Ringbom, ${ }^{1}$ (D) A. Axelsson, ${ }^{1}$ O. Bü̈nnham, ${ }^{1}$ N. Brännström,${ }^{1}$ T. Fritioff, ${ }^{1}$ H. Grahn, ${ }^{1}$ S. Hennigor, ${ }^{2}$ and \\ M. Olsson ${ }^{2}$
}

\begin{abstract}
An analysis of a data set consisting of 3 years of high time resolution radioxenon stack measurements from the three nuclear reactors at the Forsmark nuclear power plant in Sweden, as well as measurements of atmospheric radioxenon in Stockholm air, $110 \mathrm{~km}$ away, is presented. The main causes for the stack releases, such as the function of the xenon mitigation systems, presence of leaking fuel elements, and reactor operations such as shutdown and startup, are discussed in relation to the stack data. The relation between radioxenon releases and reactor operation is clearly illustrated by the correlation between the stack measurements and thermal reactor power. In general, the isotopic ratios of the Stockholm measurements, which are shown to mainly originate from Forsmark releases, agree well with stack measurements, and with a modeled reactor operational sequence. Results from a forward atmospheric dispersion calculation agree very well with observed plume arrival times and widths, and with some exceptions, also with absolute activity concentrations. The results illustrates the importance of detailed knowledge of radioxenon emissions from nuclear power plants when interpreting radioxenon measurements for nuclear test ban verification, and provide new input to this kind of analysis. Furthermore, it demonstrates the possibility to use sensitive radioxenon detection systems to remotely detect and verify reactor operation.
\end{abstract}

Keywords: CTBT, radioxenon, environmental monitoring, nuclear reactor, treaty verification.

\section{Introduction}

The dominating release source for the radioactive xenon (radioxenon) routinely found in the atmosphere are medical isotope production facilities (IPFs) (Saey et al. 2010), which are estimated to contribute to $95 \%$ of the global ${ }^{133} \mathrm{Xe}$-activity of about $50 \mathrm{TBq}$ released daily (Achim et al. 2016). The

1 Swedish Defence Research Agency (FOI), 16490 Stockholm, Sweden. E-mail: anders.ringbom@foi.se

2 Forsmarks Kraftgrupp AB, 74242 Östhammar, Sweden. remaining 5\% is mainly due to nuclear power plants (Kalinowski and Tuma 2009). Although nuclear reactors are typically weak radioxenon sources compared to IPFs, they still can be very important to take into account when interpreting potential nuclear explosion signals detected in the radioxenon network of the International Monitoring System (IMS) used for verification of the Comprehensive Nuclear-Test-Ban Treaty (CTBT)(CTBTO 2019). There are many power reactors, in particular in the northern hemisphere, and occasionally they can emit quite sizable amounts of radioxenon compared to what is released normally (Kalinowski and Tuma 2009). If the reactor(s) are close to an IMS station, they can actually be the dominating background source, as will be shown in this report.

Furthermore, even though radioxenon signatures from nuclear power reactors typically are different from a fresh (i.e. xenon separated early) nuclear explosion signal (Kalinowski et al. 2010), we cannot always expect fresh nuclear explosion radioxenon to be released. In addition, surprisingly many atypical releases from power reactors, both with respect to isotopic ratios and released activities, have been detected through the years. It is therefore important for the CTBT verification regime to gain as much knowledge as possible on the radioxenon signatures from nuclear power plants.

The main causes for radioxenon releases into the atmosphere from nuclear power plants are leaking fuel assemblies and fission of so called "tramp uranium"-uranium particles located outside the fuel (see for instance Lewis et al. 2017). The xenon that diffuses from the fuel matrix is normally mitigated in the reactor exhaust system, where delaylines based on 
e.g. charcoal and/or sandbeds are used to allow most of the radioxenon to decay away before the air is being released through the stack. But these mitigation systems may not always be fully functional, or has to be by-passed in certain operational modes, sometimes causing puff or continuous radioxenon releases.

The released isotopic ratios from a nuclear power plant depend on many factors, such as the neutron flux ${ }^{1}$, which vary at for instance reactor start-up or shut-down, fractionation following diffusion from the fuel matrix, mixing of xenon batches produced at different times, and type and status of the delayline system. It is important to have good knowledge of the possible range of these ratios, as well as to understand their origin, since they are used when discriminating between nuclear explosions and other sources.

One example of an earlier study of atmospheric radioxenon releases from a nuclear power plant can be found in (Saey et al. 2013). Another, more extreme case, is the large xenon release from the Fukushima Dai-ichi nuclear power plant in 2011, where almost the whole xenon inventory was released (see Eslinger et al. 2014 and references therein).

In this paper we present an analysis on an extensive set of measurements of radioxenon releases from a nuclear power plant. Data consists both of stack measurements performed by the plant operator, as well as high-time resolution atmospheric measurements performed by The Swedish Defence Research Agency (FOI) in Stockholm, 110 km south of the plant, during the same time period.

In Sect. 2 the stack data set is reported, along with an analysis of activities and isotopic ratios compared to reported reactor operation and simulations. This is followed in Sect. 3 by a presentation and analysis of the atmospheric measurements, and a comparison of these measurements with regional particle dispersion

\footnotetext{
${ }^{1}$ The radioxenon isotopes of interest are short-lived fission products and therefore at any given specific power in the reactor fuel build up relatively quickly to an equilibrium activity. However, they are also removed through radiative absorption of neutrons, which in the case of ${ }^{135} \mathrm{Xe}$ (with a large absorption cross section) introduces a noticeable non-linear dependence on the neutron flux. The increase in equilibrium activity will therefore not be proportional to a power increase, as is the case with the other radio-xenon isotopes of interest (with orders of magnitude lower absorption cross sections). This will cause the ${ }^{135} \mathrm{Xe} /{ }^{133,131 m, 133 m} \mathrm{Xe}$ ratios to decrease with increased power.
}

modeling performed using the stack data as input in Sect. 4. Summary and conclusions are found in Sect. 5 .

\section{Stack Measurements from The Forsmark Nuclear Power Plant}

Sweden has eight operating nuclear power reactors, distributed on three different sites (see Fig. 1), Ringhals (one BWR and three PWRs), Oskarshamn (one BWR), and Forsmark (three BWRs).

The origins of the radioxenon in Stockholm air are releases from many sources in Europe [and also from sources outside Europe, in particular before the closing of the Chalk River IPF in Canada in October 2016 (Hoffman and Berg 2018)], but as will be shown in this report, releases from the Forsmark plant constitute a large part. The Forsmark plant is located only $110 \mathrm{~km}$ north of Stockholm, and has been releasing, in a CTBT-verification context, relatively large amounts of radioxenon in the last few years. It is therefore interesting to study this radioxenon source in some detail in order to understand the observations in Stockholm.

In this section, we first give a brief description of the mitigation system used to reduce the radioxenon releases, as well as of the stack measurement system, since this is important in order to to understand the stack data. We then present a 3-year data set with

${ }^{133} \mathrm{Xe}$-measurements. This is followed by the analysis of a data set containing both ${ }^{133} \mathrm{Xe}$ and ${ }^{135} \mathrm{Xe}$, and compare this to the power output of the reactors, in order to investigate the dependence of activities and the ${ }^{135} \mathrm{Xe} /{ }^{133} \mathrm{Xe}$ ratio on reactor operation. Finally, we use a third data set, containing all four CTBTrelevant radioxenon isotopes, and compare this to a specific reactor shutdown-startup sequence, which is also modeled.

\subsection{The Reactor Exhaust System}

The noble gases contained in the steam from each reactor in the Forsmark plant are delayed in a system consisting of two sandbeds and three charcoal columns, of which two are used simultaneously. 


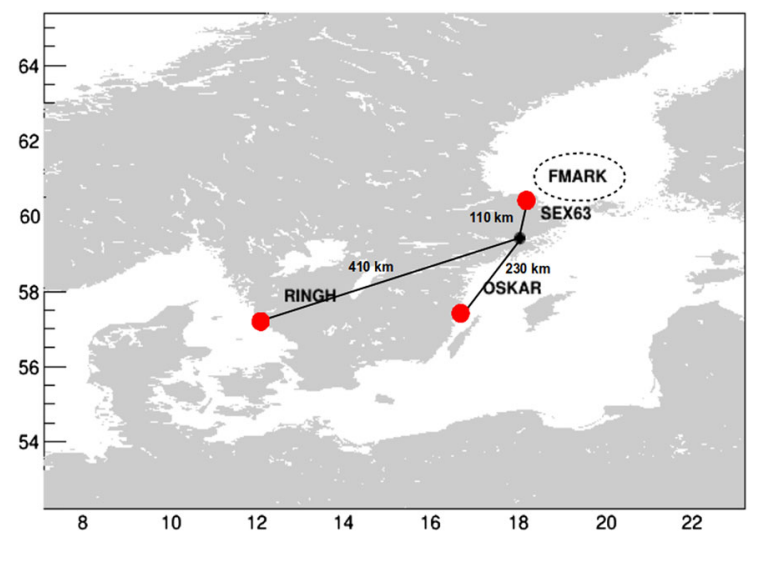

Figure 1

Map showing the locations of the three operating nuclear power plants in Sweden (red dots) and their distance to the FOI headquarters in Stockholm, where two noble gas systems are located: SAUNA II used at IMS station SEX63, and a newly developed SAUNA III system, operated by FOI at the same location. The longitude ( $\mathrm{x}$ axis) and latitude (y axis) are also indicated

The gas is delayed in the first sandbed for 15-20 h. After this, the gas is further delayed in the charcoal columns where the gas is back-flushed several times, resulting in an effective delay of 100 of hours. This is particularly important for reducing the relatively long-lived ${ }^{133} \mathrm{Xe}$ isotope. The gas is then streamed through the second sandbed, which adds an additional 15-20 h of delay, and finally the gas is passed through a particulate filter separating iodine and other aerosols before released through the stack with a total airflow of $100-150 \mathrm{~m}^{3} / \mathrm{s}$. Two reactors have a stack height of $130 \mathrm{~m}$ while the third has a stack height of $100 \mathrm{~m}$. Most of the air flow is due to air from the ventilation system, only a small part comes from the delayline. The uppermost part of the tank containing the second sandbed is not filled all the way to the top. Instead it is used to delay steam leaking from the turbine system by about one minute. This steam constitutes about $0.1 \%$ of the total air flow, and cannot be passed through the complete delayline, since it is mixed with a large air volume. Finally, it is important to be aware of that the mitigation system has to be partly by-passed in certain operational modes, in particular when the reactor power is ramped up or down. The reason is that the delayline depend on upstream vacuum created by the turbine condensers.

\subsection{The Stack Monitoring System}

Following the aerosol filter, but before the gases are released, a nuclide-specific measurement is performed on a small part of the air flow $(0.6 \mathrm{l} / \mathrm{s})$. The measurement is performed using two coaxial HPGe detectors, each with a relative efficiency of $15 \%$. The detectors are mounted inside 101 containers with Marinelli geometry, and measure the activity concentration in the container with a time resolution down to $15 \mathrm{~min}$. The released activity (in $\mathrm{Bq} / \mathrm{s}$ ) is calculated by scaling with the total air flow. Since the measurement is performed immediately before the gas is released, no decay correction is needed.

\subsection{Stack Measurements of ${ }^{133} \mathrm{Xe}$}

Stack measurements of ${ }^{133} \mathrm{Xe}$ activities for all three reactors for the time period Jan 1, 2016 to Feb 2, 2019, are shown in Fig. 2. The activities have been integrated into 6-h bins and are shown separately for each reactor (F1, F2, and F3). The minimum detectable activity (MDA) for ${ }^{133} \mathrm{Xe}$ at 6-h time resolution is around $2 \mathrm{GBq}$. As can be seen in the figure, the activities show a large variability, both between different reactors, as well as at the same reactor. The activities vary more than two orders of magnitude, with a highest released 6-h integrated activity of $7.6 \times 10^{11} \mathrm{~Bq}$, released by F1 in Feb 2017 .

When the reactors operate routinely, and when the delaylines are working properly, the released activities are normally below the detection limit. But during the time period shown here, all three reactors have been subject to problems with leaking fuel elements as well as with the mitigation systems.

Releases by F1 occurred mainly during two time periods, one in the first half of 2017, and the other in the spring and summer of 2018. As can be seen, the releases occurred in both periods more or less on a daily basis. The reason for this is damaged fuel in combination with a not fully functional delay system, the latter causing fresh xenon to be released daily.

The explanations for the releases from reactor F2 starting in late 2018 are similar. A fuel damage occurred in November 2018, and there was breakthrough in the back-flushed charcoal beds in the 

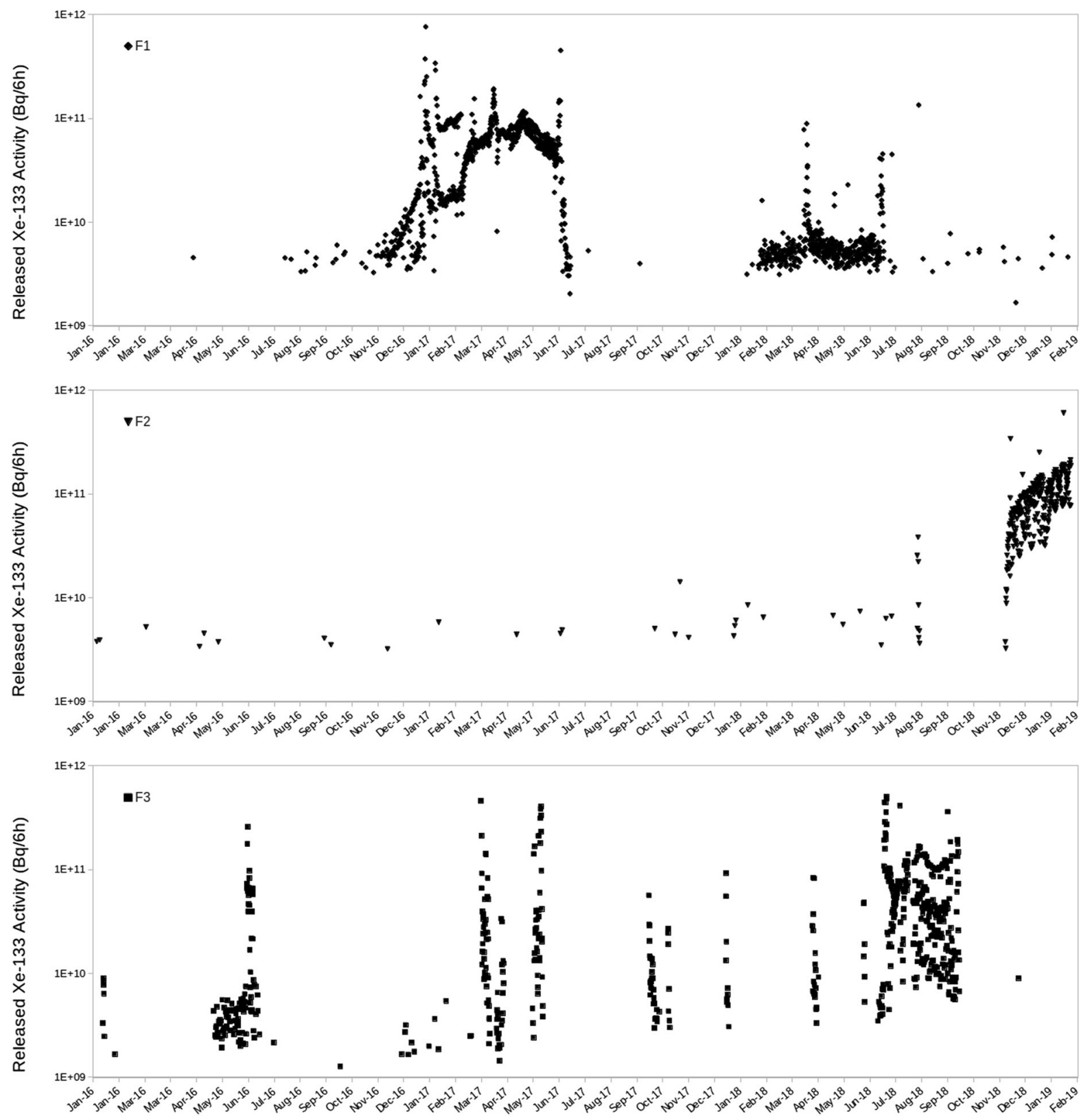

Figure 2

Measured ${ }^{133} \mathrm{Xe}$ activities released from the stacks of the three reactors (F1, F2, and F3) at the Forsmark nuclear power plant. Data are for the time period Jan 1, 2016 to Feb 2, 2019. The measurements are integrated into 6-h bins

delayline. The back-flushing frequency can be observed as a periodicity in the released ${ }^{133} \mathrm{Xe}$ activity.

Frequent radioxenon releases from $\mathrm{F} 3$ is also evident in the data. In contrast to F1 and F2, reactor F3 had a fully functional mitigation system. The releases are instead correlated with non-routine operations involving shut-down and start-up, partly conducted in order to address the damaged fuel issue. This is the reason that the releases occur more in the form of individual peaks compared to F1 and F2. See the next section for a more detailed discussion on this topic. 

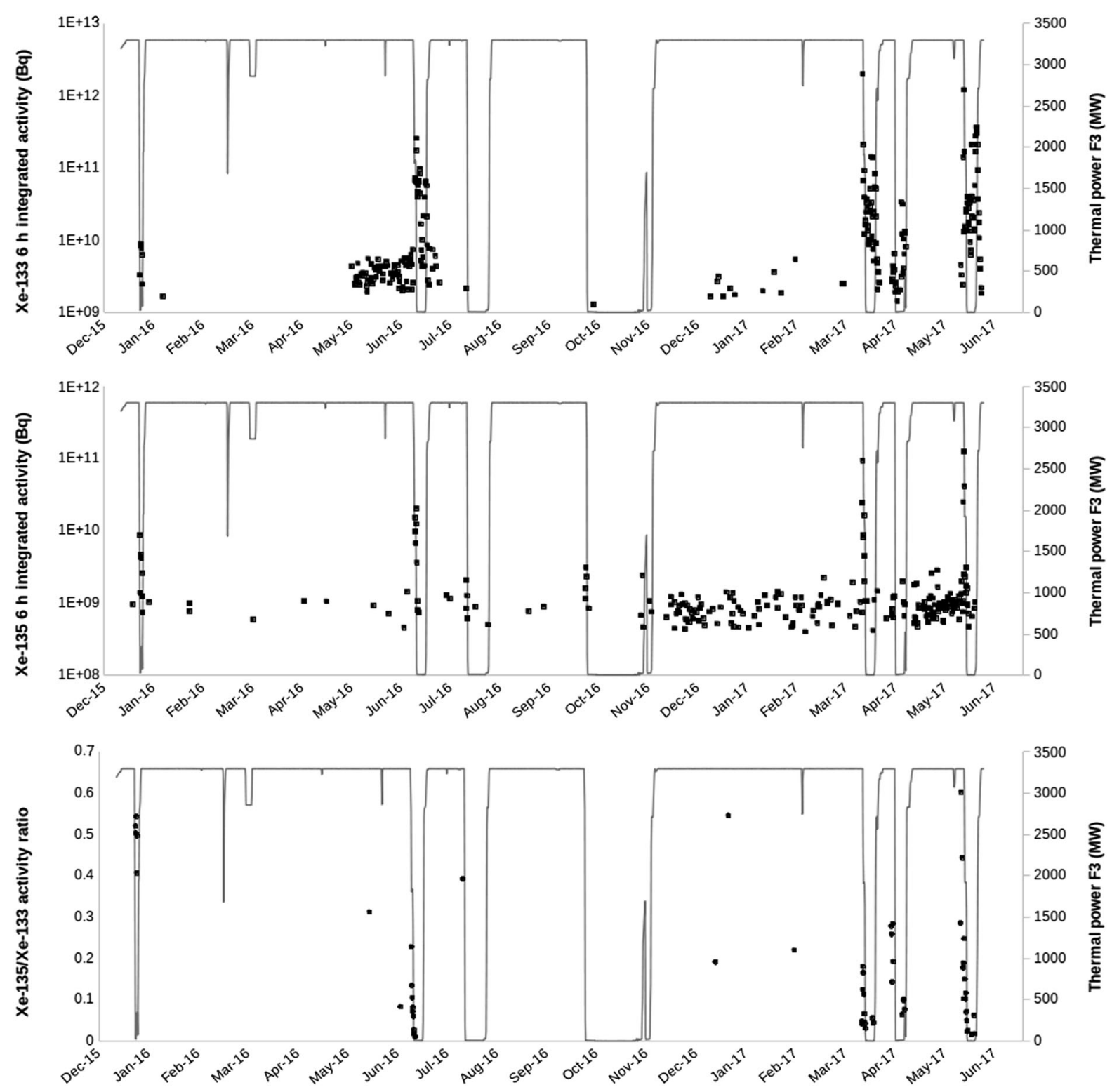

Figure 3

Stack measurements for reactor F3 plotted together with thermal power. Activities for ${ }^{133} \mathrm{Xe}$ and ${ }^{135} \mathrm{Xe}$ in six-hour bins are displayed in the top and middle panels (black dots), while the black dots in the bottom panel show the ${ }^{135} \mathrm{Xe} /{ }^{133} \mathrm{Xe}$ activity ratio. The thermal power is shown as a gray line in all diagrams

\subsection{Stack Releases Compared To Thermal Reactor Power}

To further investigate the correlation between radioxenon releases and reactor operation, stack measurements were compared to the thermal power of the reactors. For this purpose, a shorter data set was used, ranging from January 1, 2016, to June 7,
2017, but this time consisting of 6-h measurements of both ${ }^{133} \mathrm{Xe}$ and ${ }^{135} \mathrm{Xe}$. The MDA for ${ }^{135} \mathrm{Xe}$ was about $0.6 \mathrm{GBq}$ per 6-h period.

Figure 3 shows these measurements for F3 plotted together with the thermal power of the reactor. As the figure shows, the way the reactor is operated, indicated with the power output, clearly correlates 

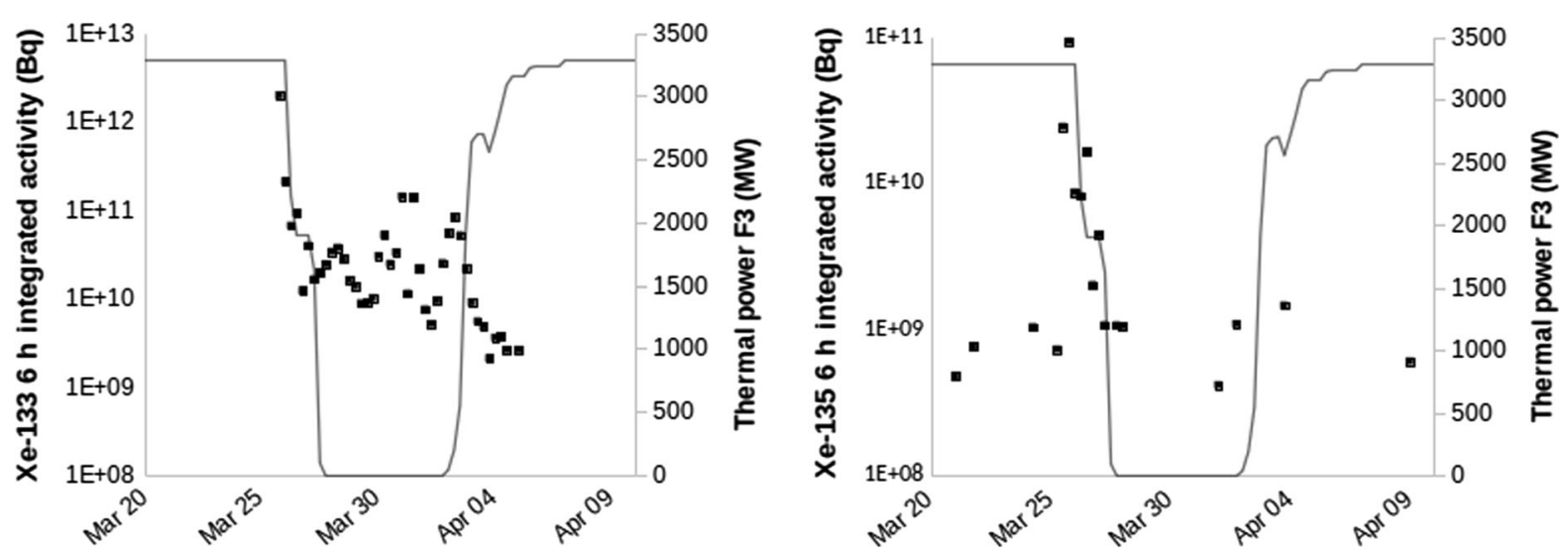

Figure 4

Stack measurements for reactor F3 plotted together with thermal power (gray lines). Activities for ${ }^{133} \mathrm{Xe}$ (left) and ${ }^{135} \mathrm{Xe}$ (right) are shown as black points. Data was collected during a shutdown-startup performed in March-April 2017

with the radioxenon releases. Both the ${ }^{133} \mathrm{Xe}$ - and ${ }^{135} \mathrm{Xe}$ activities increase by several orders of magnitude when the reactor power is changed. As mentioned above, the delaylines have to be partly by-passed during these operations, resulting in batches of radioxenon releases. The xenon peaks are most pronounced when the power is ramped down, in particular for ${ }^{135} \mathrm{Xe}$. As can be seen in the bottom figure, the majority of the detected ${ }^{135} \mathrm{Xe} /$ ${ }^{133} \mathrm{Xe}$ ratios also occur when the power is decreased. The ratios then are in the range 0.6-0.1. But they also occasionally appear when the reactor is started up again, but then with a lower ratio (around 0.1). In contrast to ${ }^{135} \mathrm{Xe}$, the ${ }^{133} \mathrm{Xe}$ activity is also often increased when the reactor power is ramped up. As also can bee seen in Fig. $4,{ }^{135} \mathrm{Xe}$ is detected without ${ }^{133} \mathrm{Xe}$ at several occasions. This is most likely a detection limit feature.

To illustrate this in more detail, the figures are zoomed in to show a reactor shutdown and startup sequence performed between the end of March and the beginning of April, 2017. The reactor was stopped in order to take care of damaged fuel elements. The ${ }^{135} \mathrm{Xe}$ activity increases in this case only when the power is ramped down, while several puffs of ${ }^{133} \mathrm{Xe}$ is observed also at later times, including a peak when the reactor is started up again. One explanation for the increase of the latter isotope is release of ${ }^{133} \mathrm{Xe}$ adsorbed in the mitigation system.
The radioxenon releases from reactor $\mathrm{F} 1$ behave differently. In this case the mitigation system was not fully functional, and since F1 has damaged fuel elements constantly creating radioxenon in the water, fresh xenon containing both ${ }^{133} \mathrm{Xe}$ and ${ }^{135} \mathrm{Xe}$ is released daily when the reactor is operating at full power. This is illustrated in Fig. 5, showing the measured ${ }^{135} \mathrm{Xe} /{ }^{133} \mathrm{Xe}$ ratio as a function of time. Also in this case, ratios up to 0.6 were observed.

\subsection{A Closer Look at The Isotopic Ratios}

The shutdown of F3 in March-April 2017 was studied in even more detail by using a data set with stack data from F3 containing 30-minute measurements of all CTBT-relevant isotopes, ${ }^{133} \mathrm{Xe},{ }^{131 m} \mathrm{Xe}$, ${ }^{133 m} \mathrm{Xe}$, and ${ }^{135} \mathrm{Xe}$.

The activities and isotopic ratios for this data set are shown in Fig. 6. Note that this time the reported release rate is used (in $\mathrm{kBq} / \mathrm{s}$ ). To get the integrated activity, all numbers should be multiplied with the $1800 \mathrm{~s}$ long integration period.

The upper panel of Fig. 6 now shows the variation of the ${ }^{133} \mathrm{Xe}$ - and ${ }^{135} \mathrm{Xe}$ activities in more detail compared to Fig. 4. In the middle panel we also see that there are some detections of the metastable isotopes ${ }^{133 m} \mathrm{Xe}$ and ${ }^{131 m} \mathrm{Xe}$. However, some of them are quite close to the detection limit, and thus associated with relatively large uncertainties (not reported). The ${ }^{131 m} \mathrm{Xe}$ measurements are few, and show no clear 


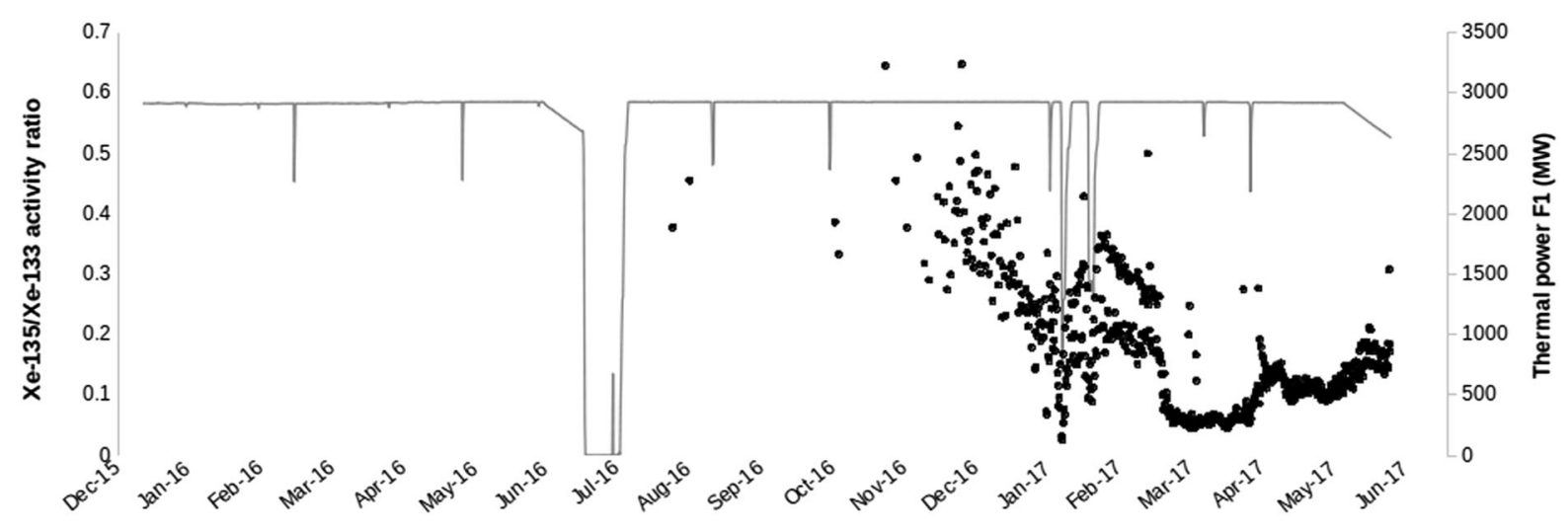

Figure 5

Stack measurements of the ${ }^{135} \mathrm{Xe} /{ }^{133} \mathrm{Xe}$-ratio (black dots) for reactor F1 plotted together with thermal power (gray lines)

time-dependence, while there is an increase of ${ }^{133 m} \mathrm{Xe}$ at reactor shutdown. Some of the ${ }^{133 m} \mathrm{Xe} /$ ${ }^{133} \mathrm{Xe}$ ratios are close to one, which is higher than predicted from calculations (see next section). If the ${ }^{133 m} \mathrm{Xe} /{ }^{133} \mathrm{Xe}$ ratios are measured to be close to the MDA, these ratios can be associated with large uncertainties. However, it is not impossible that under certain operational conditions, newly irradiated and separated radioxenon reaches the stack measurement system. We are not able to draw any definite conclusions regarding this in the present report.

The observed ${ }^{133 m} \mathrm{Xe} /{ }^{133} \mathrm{Xe}$ ratios can be compared with what is measured and calculated by the plant operators at other occasions, and at other places in the reactors. The plant calculated a production ratio of about 0.08 , assuming realistic contributions from leaking fuel elements and tramp uranium. The calculated ratio in the off-gases, before reaching the delayline, is $0.04-0.05$, and was measured to be $0.03-$ 0.06 at F1 in the spring 2017. Stack data from the same period showed a ratio of 0.03 downstream from the delayline, indicating that the mitigation system was not fully functional. In contrast, the stack ${ }^{133 m} \mathrm{Xe} /$ ${ }^{133} \mathrm{Xe}$ ratio was measured to be 0.01 in August 2018 at reactor F3, which had a properly working delayline.

\subsection{Stack Data Compared to Model Calculations}

As discussed, many different mechanisms can be responsible for the levels and isotopic composition of radioxenon released from a nuclear power plant, including reactor design and power history, damaged fuel elements, mixing of different gas batches, and type and status of mitigation system. To model this in detail in each specific case would be very difficult, but the main expected time dependence of the different isotopic ratios is nevertheless valuable when observations are interpreted, for instance when discriminating between releases from nuclear explosions and other radioxenon sources (Kalinowski et al. 2010).

Time-dependent radio-xenon inventories were therefore calculated for typical low-enriched BWR fuel (ABB $8 \times 8$ design) using the ORIGEN-ARP depletion analysis sequence of the SCALE code package (Rearden and Jessee 2016). Different cycles of operation, each defined by specific thermal power (MW per metric ton of uranium, or MTU) as a function of time, were studied. In Fig. 7, showing two different multi-isotope plots, the full curve shows a "standard" cycle with 300 days of operation at a specific power of $35 \mathrm{MW} / \mathrm{MTU}$ followed by 30 days at very low power ( $350 \mathrm{~W} / \mathrm{MTU})$, followed by another 300 days at $35 \mathrm{MW} / \mathrm{MTU}$. The dashed curve represents the situation during the shutdown of F3 in March-April 2017 discussed in Sect. 2.4 and illustrated in Fig. 4, and defined for the purposes of the ORIGEN-ARP calculation by power settings communicated by the operator: a ramping down of power from about $30 \mathrm{MW} / \mathrm{MTU}$ to about $50 \mathrm{~kW} / \mathrm{MTU}$ over a period of about $36 \mathrm{~h}$, a period of a little over $100 \mathrm{~h}$ at this low power, and finally a ramping up of power to about $30 \mathrm{MW} / \mathrm{MTU}$ over a period of $72 \mathrm{~h}$. 

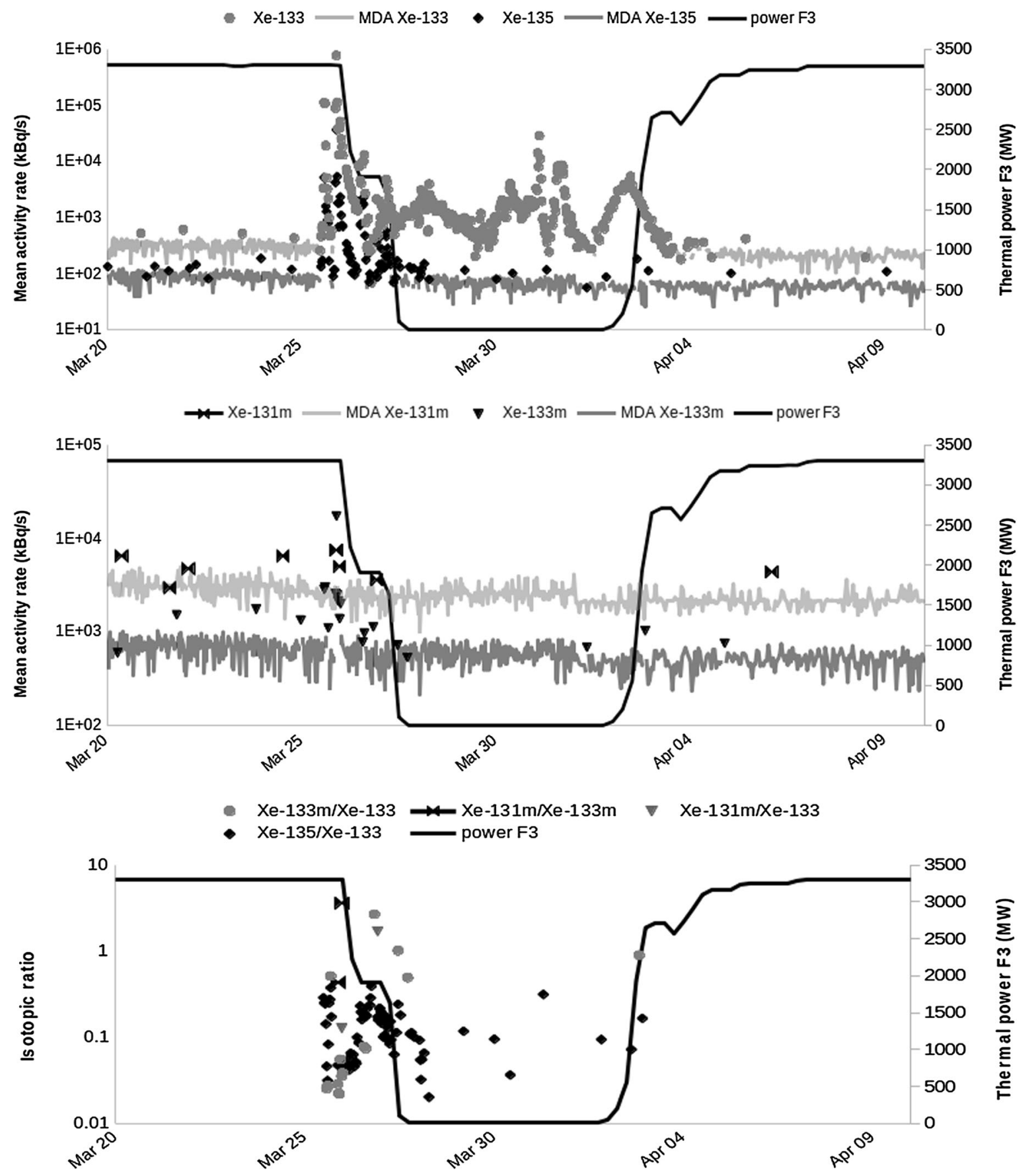

Figure 6

30-min stack measurements of ${ }^{133} \mathrm{Xe},{ }^{131 m} \mathrm{Xe},{ }^{133 m} \mathrm{Xe}$, and ${ }^{135} \mathrm{Xe}$ made during the F3 shutdown-startup performed in March-April 2017. The upper panel shows measurements of ${ }^{133} \mathrm{Xe}$ and ${ }^{135} \mathrm{Xe}$, together with reported MDA in the case the isotope was not detected. The thermal power of F3 is also shown. The middle panel shows corresponding data for ${ }^{133 m} \mathrm{Xe}$ and ${ }^{131 m} \mathrm{Xe}$, while detected isotopic ratios are displayed in the bottom panel

Measurements where ${ }^{133} \mathrm{Xe},{ }^{133 m} \mathrm{Xe}$, and ${ }^{135} \mathrm{Xe}$ all were detected simultaneously are shown as black dots in the left panel of Fig. 7 (compare to Fig. 6). Most ratios are found where equilibrium xenon is expected 

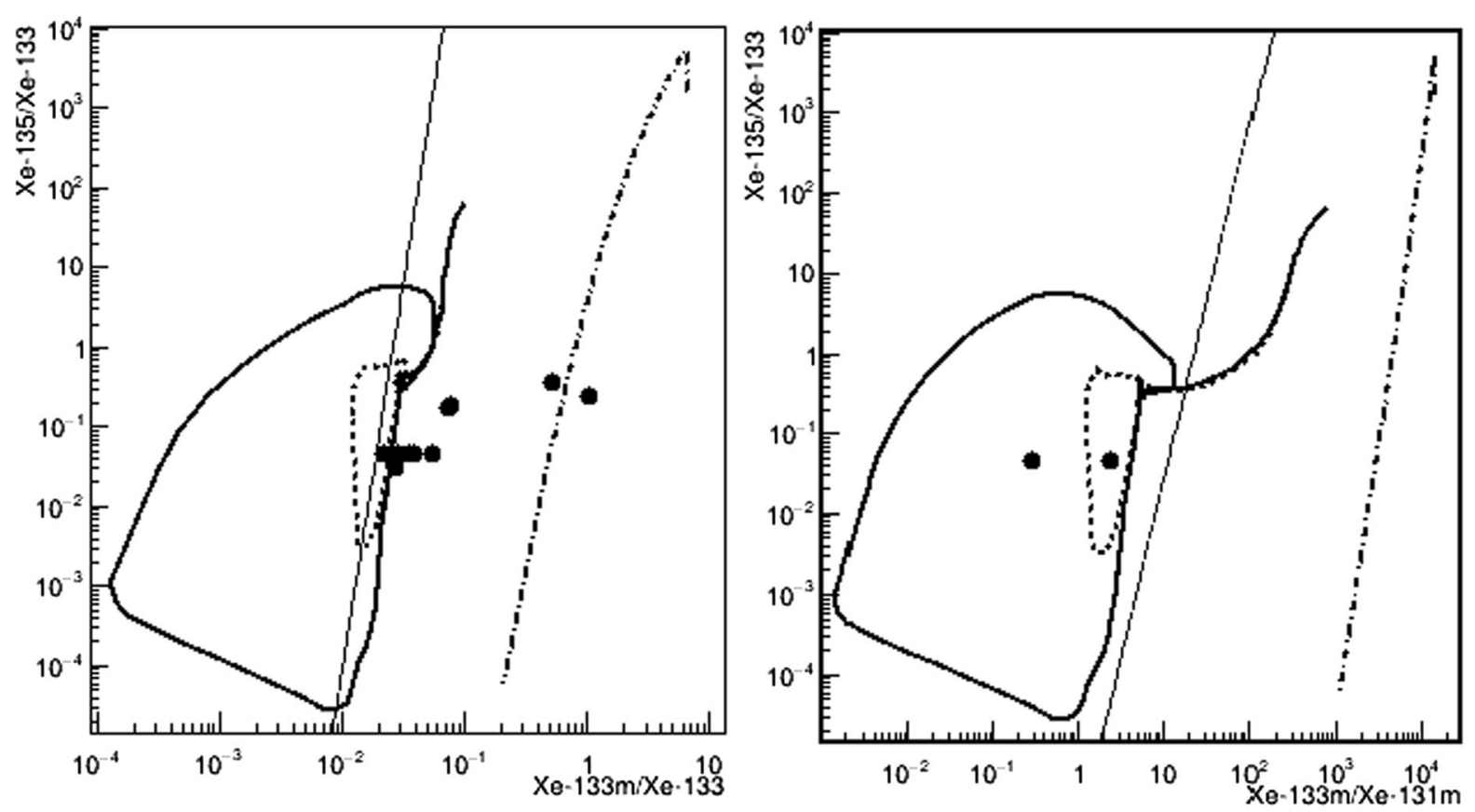

Figure 7

A three- (left panel) and a four-isotope (right panel) plot with calculated reactor scenarios and stack data observed during the shutdown-startup of F3 in March-April 2017 (black dots). The thick solid line describes a calculated cycle with 300 days of operation at high power followed by 30 days at very low power, then followed by another 300 days at high power. The dashed line is a similar simulation of the shutdownstartup of F3 in March-April 2017, while the dot-dashed line to the right shows expected ratios from prompt fission of ${ }^{235} \mathrm{U}$ from,e.g., an early release from a nuclear test. The thin solid line is the discrimination line according to Kalinowski et al. (2010)

to be located, following a decay of about 2 days. One possible explanation is that this is equilibrium xenon delayed in the mitigation system, and released during shut-down. Two data points have ${ }^{133 m} \mathrm{Xe} /{ }^{133} \mathrm{Xe}$ ratios of about 1 , close to the line describing prompt fission and release of ${ }^{235} \mathrm{U}$. But as discussed above, a likely explanation is that they are associated with large uncertainties. However, other explanations cannot be excluded.

Only two measurements in the data set contained all four CTBT-relevant radioxenon isotopes. They are shown in the right panel of Fig. 7. One data point ends up to fit well with the simulated shutdown, while the other has a smaller ${ }^{133 m} \mathrm{Xe} /{ }^{131 m} \mathrm{Xe}$ ratio than predicted. One explanation could be mixing of different radioxenon batches, one containing "older" xenon with more ${ }^{131 m} \mathrm{Xe}$. This could be caused by ${ }^{131} \mathrm{I}$ trapped in the charcoal columns, decaying to ${ }^{131 m} \mathrm{Xe}$.

As Fig. 7 shows, the detection of ${ }^{131 m} \mathrm{Xe}$ can be important when discriminating releases from nuclear weapon tests and other sources. One way to increase this sensitivity in the IMS would be to re-measure important samples in the laboratory using longer measurement times.

\section{Analysis of Atmospheric Measurements in Stockholm}

\subsection{Measurement Data Set}

Since 2005, FOI in Stockholm is operating the IMS noble gas station SEX63, which is equipped with a SAUNA II system (Ringbom et al. 2003), measuring air samples with a collection time of $12 \mathrm{~h}$, and a collected air volume of about $15 \mathrm{~m}^{3}$. Many plumes from the Forsmark plant, located $110 \mathrm{~km}$ north of the station, has been detected with this system through the years. Furthermore, FOI also has a prototype of the next generation of SAUNA systems, SAUNA III (Ringbom et al. 2017; Fritioff et al. 2017), running since 2017. This system produces air samples with $6 \mathrm{~h}$ time resolution and a volume corresponding 
to about $40 \mathrm{~m}^{3}$ of air, resulting in higher measurement sensitivity compared to the SAUNA II. In addition, the shorter collection time makes it possible to observe finer plume structures, which is useful for the atmospheric transport modeling used for estimating source parameters, such as released activity and source location.

For the work presented here, a data set measured between July 1, 2017 and January 31, 2019, was used. This set consists of 1115 12-h samples collected by the IMS station SEX63, and 2072 6-h samples measured by the SAUNA III prototype. The systems are installed less than $100 \mathrm{~m}$ apart. All data was analysed using a new spectrum analysis method (submitted for publication), with an improved statistical treatment for low-activity samples. This results in a false detection rate closer to the desired confidence level, in particular for the metastable radioxenon isotopes, compared to the method presently used by many institutions (Axelsson and Ringbom 2003; De Geer 2007).

The increased sensitivity of the SAUNA III system compared to SAUNA II is illustrated by the fraction of samples in the data set found to contain activity above the critical limit of detection (see Table 1). In particular, the critical limit for the most short-lived isotope ${ }^{135} \mathrm{Xe}$ is decreased by a factor of two, resulting in a detection rate increasing from $6 \%$ in SAUNA II to $12 \%$ using SAUNA III in this particular data set (using a confidence level of $95 \%$, resulting in a false detection probability of $5 \%$ ). The ${ }^{135} \mathrm{Xe}$ detections are believed to come almost exclusively from Forsmark releases, as shown in Sect. 3.2.

Measured levels of ${ }^{133} \mathrm{Xe}$ in Stockholm air are shown in Fig. 8. The figure show data from both

Table 1

Fraction of samples where the isotope is detected, assuming a confidence level of $95 \%$

\begin{tabular}{lll}
\hline & SAUNA II $(\%)$ & SAUNA III $(\%)$ \\
\hline${ }^{133} \mathrm{Xe}$ & 63 & 77 \\
${ }^{131 m} \mathrm{Xe}$ & 17 & 34 \\
${ }^{133 m} \mathrm{Xe}$ & 10 & 13 \\
${ }^{135} \mathrm{Xe}$ & 6 & 12 \\
\hline
\end{tabular}

The samples were measured by two co-located systems during the same time period
SAUNA systems in the same plot. As can be seen, the activities agree very well between the two systems. Since the SAUNA III-system has twice the time resolution, it sometimes reveals a sharper peak shape than what is possible to observe using the SAUNA II system, as illustrated in the smaller panel, where a part of the data set is zoomed in.

\subsection{Which Plumes are Caused by The Forsmark $N P P$ ?}

To investigate the possible connection between observed plumes and the radioxenon release at Forsmark, source-receptor sensitivity (SRS) fields provided by the CTBTO International Data Centre (IDC) in Vienna, were used together with the SEX63 data. The SRS fields, calculated using atmospheric transport modelling in backwards mode, are fields describing the geospatial and temporal distribution of the air mass collected in a sample (Wotawa et al. 2003). The IDC provides SRS-fields for all IMS noble gas systems to all CTBT member states on a daily basis. In this study, we use them to investigate if the air sampled by SEX63 is connected to Forsmark within $24 \mathrm{~h}$ from the collection stop time, which is a reasonable maximum transport time given the distance of $110 \mathrm{~km}$. Using this condition, the 1115 SAUNA II samples were sorted into two groups, resulting in the activity concentration series shown in Fig. 9.

As can be seen, the two data sets are different. Almost all ${ }^{135} \mathrm{Xe}$ observations $(3.2 \%$ of the samples at the $99 \%$ confidence level), are found in air connected to Forsmark. In the other group, $1.1 \%$ of the samples contains a ${ }^{135} \mathrm{Xe}$ detection, i.e., statistically close to no detections at this confidence level. Only one clear ${ }^{135} \mathrm{Xe}$ detection was found in this group. Furthermore, the majority of the strong (higher than $10 \mathrm{mBq} / \mathrm{m}^{3}$ ) ${ }^{133} \mathrm{Xe}$ plumes are found in air connected to Forsmark, but the detection frequency was comparable (55\% in the Forsmark group vs 52\% in the other group). The ${ }^{133 m} \mathrm{Xe}$ detections show about the same detection frequency in the to groups (4.4\% vs. $4.0 \%$ ), while ${ }^{131 m} \mathrm{Xe}$ is observed much more frequently in the group sorted on samples not connected to Forsmark (6.\% vs. 12\%). We believe 


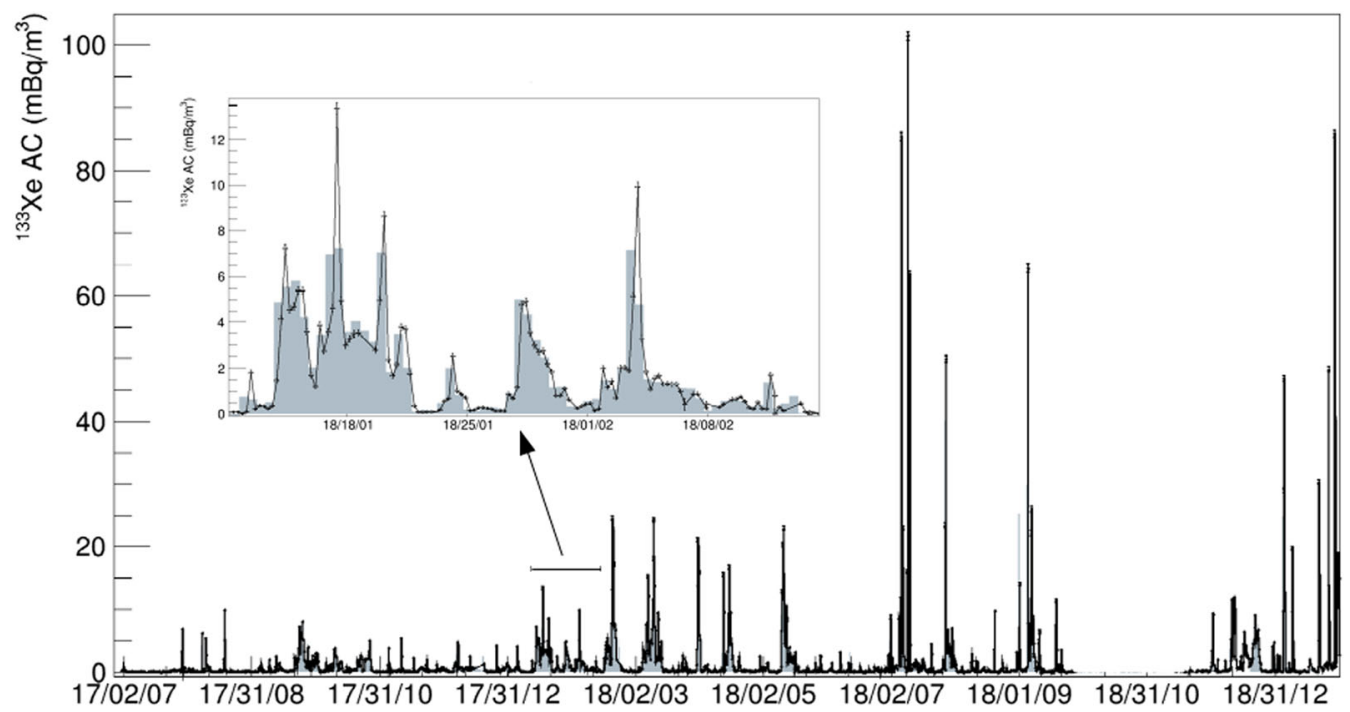

Figure 8

Measured ${ }^{133} \mathrm{Xe}$ activity concentrations in Stockholm air between July 1, 2017, and January 31, 2019. Data for two co-located systems are shown. 6-h samples measured by the FOI SAUNA III system (black line), and 12-h samples (gray area) measured by the IMS SAUNA II system at station SEX63. For better visibilty, a part of the time series is zoomed in
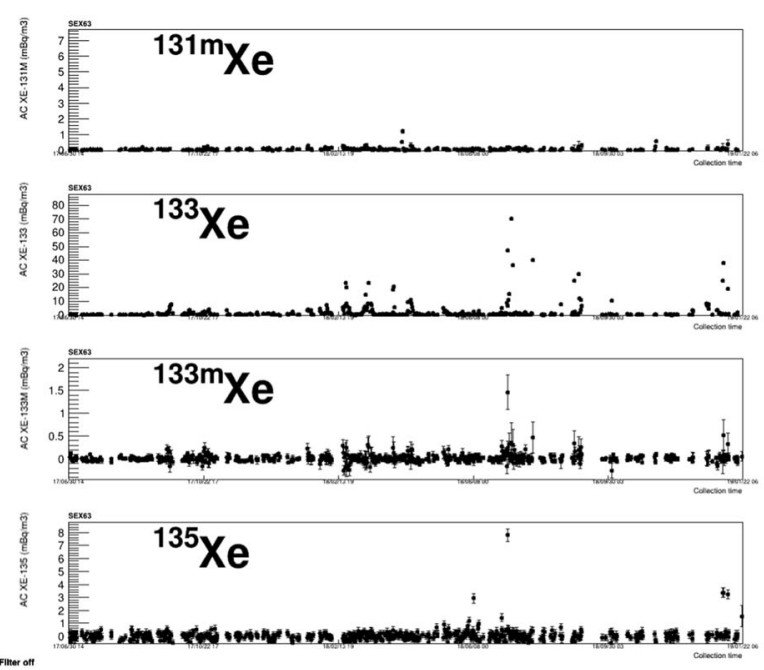

Figure 9

Radioxenon activity concentrations $\left(\mathrm{mBq} / \mathrm{m}^{3}\right)$ measured by the IMS station SEX63, sorted into two groups. The left panel shows measurements where the air is connected to the Forsmark plant within $24 \mathrm{~h}$, while the rest of the samples are displayed to the right

that this is caused by one or several IPFs in central Europe.

We conclude that the measurements in Stockholm show a large influence from Forsmark. In particular, the ${ }^{135} \mathrm{Xe}$ observations almost exclusively seem to originate from the plant. This is not a surprise, given the 9-h half-life and the short distance.
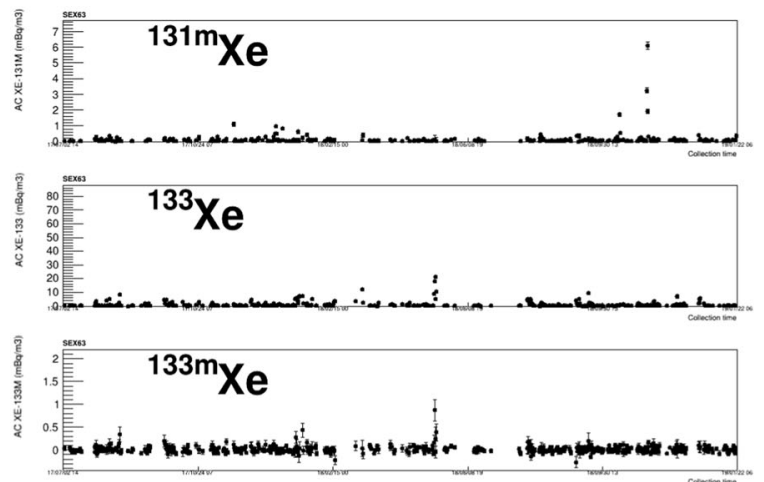

${ }^{135} \mathrm{Xe}$

\subsection{Analysis of Observed Isotopic Ratios}

Three- and four isotope ratio plots for the samples measured in Stockholm are presented in Fig. 10, together with the stack measurements and model calculations described in Sect. 2.6. Only ratios consisting of detections at the $99 \%$ confidence level are 

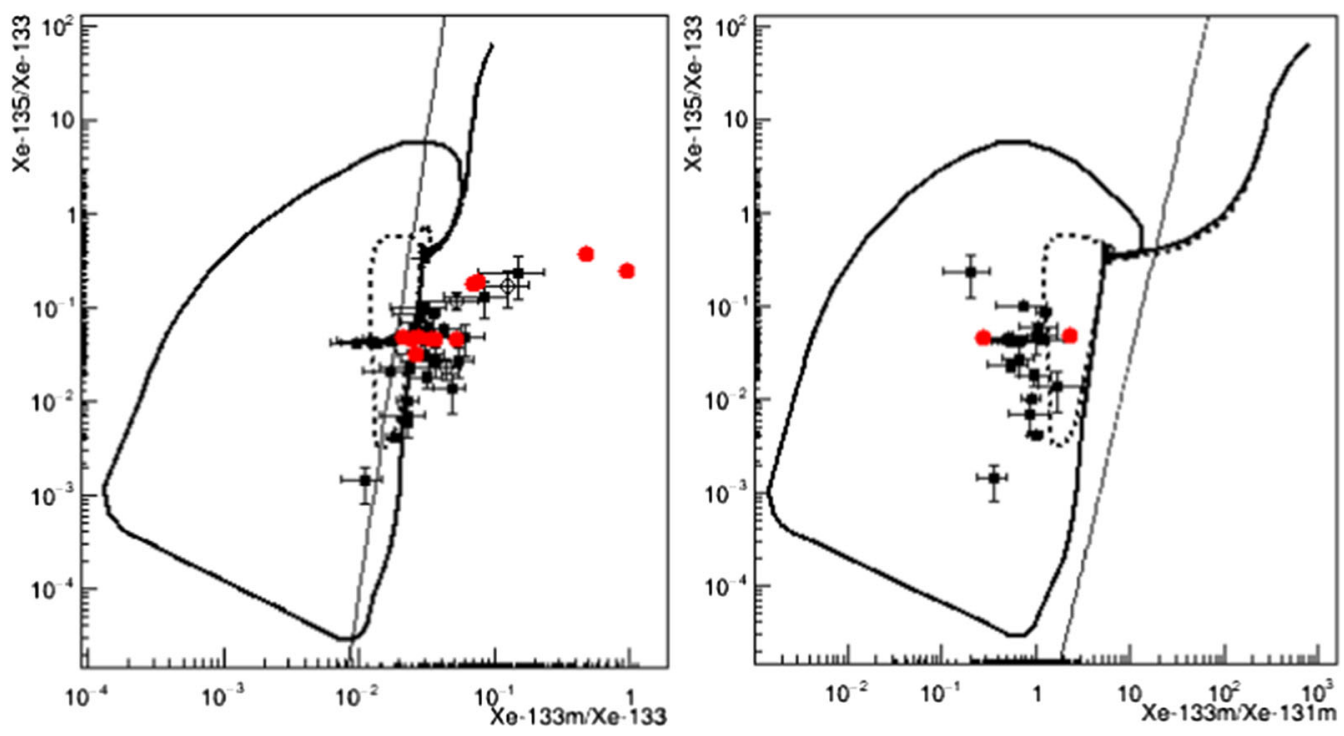

Figure 10

Three-(left) and four (right) isotope plots of the data set collected in Stockholm by the SAUNA II (white circles) and SAUNA III ( black circles) systems. Only ratios consisting of detections at the $99 \%$ confidence level are shown. Uncertainties are at the 1-sigma level. The red circles are the stack measurements discussed in Sect. 2.6, and the lines show the same reactor scenarios. The thin black line is the discrimination line according to (Kalinowski et al. 2010)

shown. Since the data requires the detection of ${ }^{135} \mathrm{Xe}$, we can expect that the Stockholm measurements are due to releases from Forsmark, as argued above. However, one cannot exclude admixture from other sources.

As can be seen, the atmospheric measurements agree well with stack data. Within uncertainties, the measurements in the three-isotope plot agree well with the calculated model, in particular if one assumes a certain decay time from the reactor to the measurement system. A decay time of $30 \mathrm{~h}$ would decrease the ${ }^{135} \mathrm{Xe} /{ }^{133} \mathrm{Xe}$-ratio by about an order of magnitude. A decay time of $30 \mathrm{~h}$ is quite realistic, taking the air transport-, sampling- and system process times into account. If all data points were shifted upwards accordingly, many observations would end up close to reactor equilibrium. We also note that a few points have ${ }^{133 m} \mathrm{Xe} /{ }^{133} \mathrm{Xe}$-ratios higher (around 0.1) that expected from a reactor in equilibrium or from a shutdown-startup. These points have relatively large uncertainties, and should therefore not be over-interpreted. However, as discussed in Sect. 2.6, there could be a contribution from fresh, early separated xenon, creating a signature more like the one observed at IPFs (Hoffman and Berg 2018).
The four-isotope plot is shifted towards lower ${ }^{133 m} \mathrm{Xe} /{ }^{131 m} \mathrm{Xe}$ ratios than predicted by the model. One explanation could be mixing of batches with older xenon, containing more ${ }^{131 m} \mathrm{Xe}$, either from the plant (as discussed in Sect. 2.6), or from other sources. Finally, it is worth pointing out that if ${ }^{133} \mathrm{Xe}$ from other sources is present in a sample, the ratios in the three-isotope plot would move left and downwards, and downwards in the four-isotope plot. Is is possible that this is the case for some of the samples.

Time series of individual ratios are shown in Fig. 11. Also here the confidence level for the individual detections is set to $99 \%$. Since now only one ratio is required to be detected, the number of data points is increased compared to Fig. 10. The simulation of a "standard" reactor cycle discussed in Sect. 2.6 is also displayed using the same time scale, to indicate expected reactor ratio intervals. The sudden ratio changes caused by the 30-day shutdown-startup cycle are visible in the middle of each graph.

The two ratios involving ${ }^{135} \mathrm{Xe}$ are found at levels within the calculated standard scenario. Again, the short half-life of this isotope should obviously be 

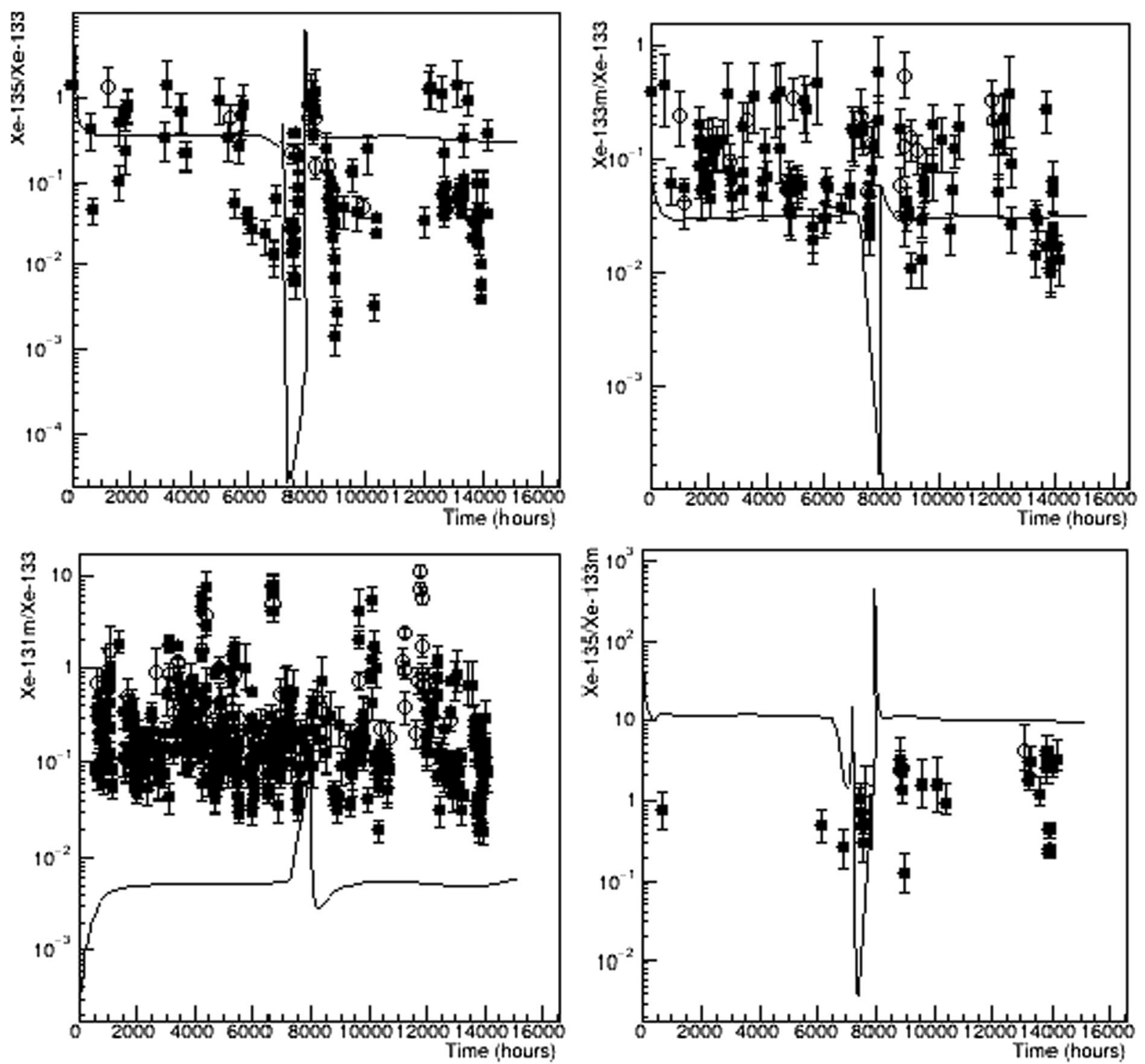

Figure 11

Time series of observed isotopic ratios in Stockholm. The black circles are SAUNA III data, and the white circles are from SAUNA II. The confidence level for the individual detections is set to $99 \%$, and the uncertainties are at the one sigma level. The simulation of a "standard" reactor cycle with 300 days operation, 30 days shutdown, and 300 days operation, is displayed using the same time scale as a black line

taken into account when interpreting the data. A low ${ }^{135} \mathrm{Xe} /{ }^{133} \mathrm{Xe}$ value does not nessecarily indicate a quick release from a reactor shutdown or startup, but could as well be an equilibrium release that has undergone decay at later stages.

Again, some of the ${ }^{133 m} \mathrm{Xe} /{ }^{133} \mathrm{Xe}$ ratios are found between 0.1 and 1 , but with relatively large uncertainties. Also, the ${ }^{131 m} \mathrm{Xe} /{ }^{133} \mathrm{Xe}$ ratios are higher than expected from routine reactor operation. As already mentioned, a very probable reason is ${ }^{131 m} \mathrm{Xe}$ from other sources.

\section{Regional Atmospheric Transport Modelling}

The data set presented here, containing 3 years of release data, as well as atmospheric measurements made $110 \mathrm{~km}$ during the same time period, offers a 
good opportunity to test atmospheric transport models. Such a test can include e.g forward dispersion calculations using stack data as input, and source localization using inverse modelling. The main focus of the present study is to present stack data in relation to reactor operation, and to analyse measured isotopic signatures, and we reserve the detailed atmospheric transport study for a future publication. However, in order to gain some further information on the impact of the Forsmark plant on the atmospheric measurements in Stockholm, we present some results from regional forward dispersion simulations using the 6-h ${ }^{133} \mathrm{Xe}$-releases as source input.

\subsection{The Atmospheric Transport Model PELLO}

PELLO is a Lagrangian random displacement model developed for long-range transport of gas and aerosols in the atmosphere. The model includes important aerodynamic processes such as dry and wet deposition along the transportation path. The model is well adapted to handle dispersion of radioactive materials and has been successfully validated (Sato et al. 2018) and applied in several studies (Björnham et al. 2017; Grahn et al. 2015).

PELLO is driven by meteorological data provided by the operational numerical weather forecast model HRES at the European Centre for Medium-Range Weather Forecasts, ECMWF. The meteorological data is based on analysis fields every $12 \mathrm{~h}$ and has spatial resolution of 0.1 degrees in both the latitudinal and longitudinal directions and temporal resolution of $3 \mathrm{~h}$. During a simulation, large amount of model particles are injected into the atmosphere and are continuously tracked during the simulated period. In each time step, all model particles are transported by the wind field while two random displacement Wiener processes are added to represent the local and mesoscale turbulences. These two processes cause the dispersion of the cloud. As the diffusion components depend on atmospheric turbulence, they vary between each meteorological grid cell since they depend on surface heat flux and surface roughness.

Releases was calcuated every six hours, using the ${ }^{133} \mathrm{Xe}$ stack data as input, together with other release parameters (stack height, airflow, outlet inner diameter, and outlet temperature) obtained from (Broed

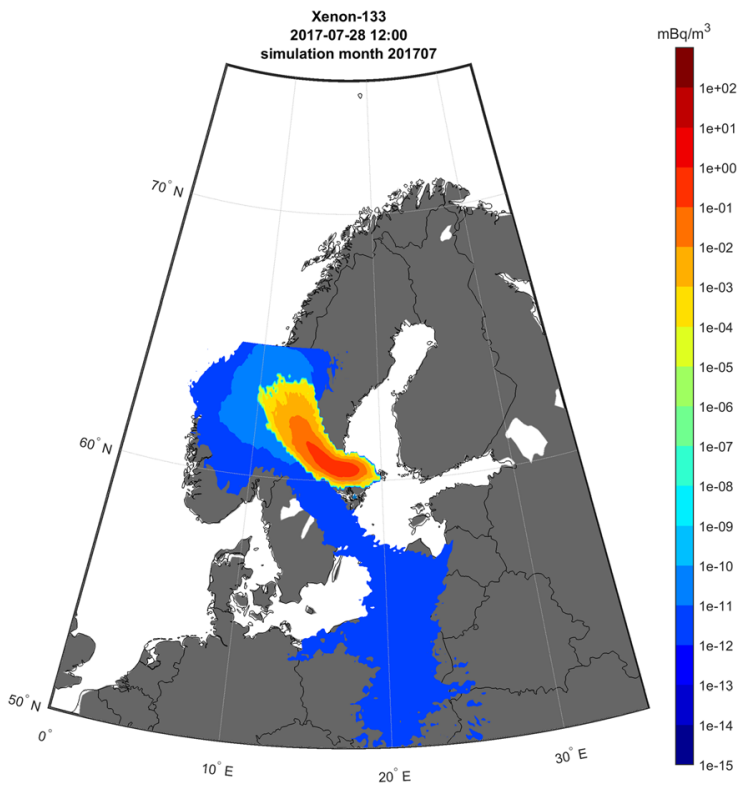

Figure 12

An example of the dispersion simulation. The latest 6-h release is visible as a plume with an activity concentration above $10^{-5} \mathrm{mBq} /$ $\mathrm{m}^{3}$ mixed with activity from a fictive release containing small traces of xenon. The fictive release is active at all times to give a representation of the dispersion pattern when we have no released activity

et al. 2017). An example of a dispersion simulation is shown in Fig. 12.

The resulting forward dilution factors from the Pello calculation were stored as SRS-fields, discussed in Sect. 3.2, and together with the ${ }^{133} \mathrm{Xe}$ stack data they were used to calculate the SAUNA II- and SAUNA III station responses. This was done using an in-house FOI code that simulates the response for any network of radioxenon stations, using a forward atmospheric dispersion result, a radioxenon source, and a parameterization of the xenon systems in the network.

\subsection{Results}

The results of the Pello calculations for the SAUNA III system in Stockholm are shown together with observations in Fig. 13. Data from two time intervals in 2018 are displayed. With very few exceptions, all predicted plumes are also observed, and the calculated arrival times and general plume 

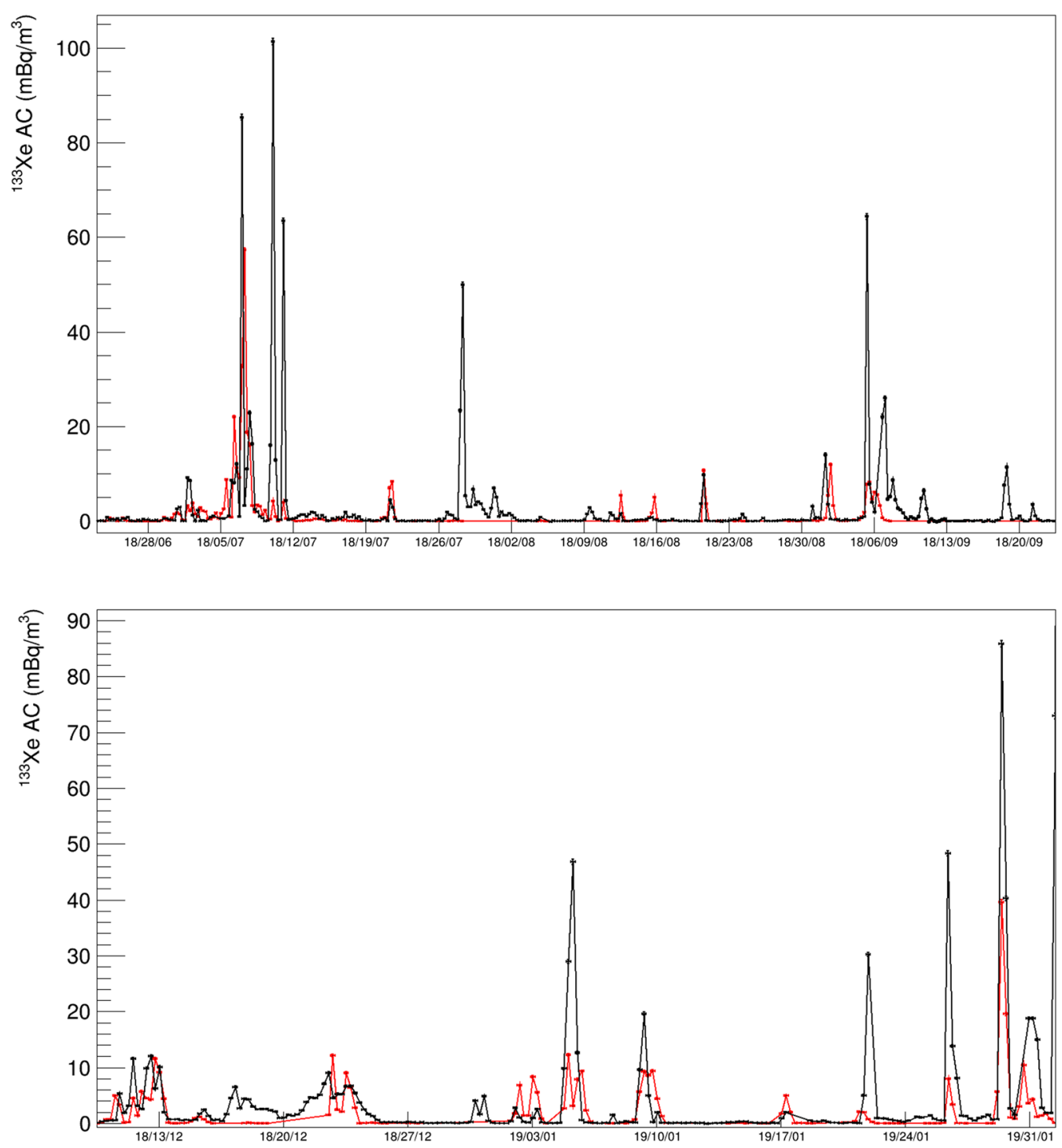

Figure 13

Simulated (red) and measured (black) ${ }^{133}$ Xe activity concentrations from SAUNA III samples with $6 \mathrm{~h}$ collection time, collected in Stockholm during two periods in 2018. The simulations include only the contribution from the Forsmark plant

shapes agree well. The absolute activity concentrations seem in general a little underestimated, although a part of this effect should be due to mixing of other sources.

\section{Summary, Conclusions and Outlook}

We presented an analysis of a data set consisting of 3 years of high time resolution radioxenon stack measurements from the three nuclear reactors at the Forsmark nuclear power plant in Sweden, and measurements of atmospheric radioxenon in Stockholm air, $110 \mathrm{~km}$ away.

The main causes for the stack releases were different for the different reactors, with the main reasons being not fully functional delaylines, fuel damages, and reactor shutdown-startups. The relation between radioxenon releases and reactor operation is clearly illustrated by the correlation between the stack 
measurements and thermal reactor power. In particular we note the increase in detectable ${ }^{135} \mathrm{Xe} /{ }^{133} \mathrm{Xe}$ ratios when the power is ramped down.

A specific reactor shutdown-startup sequence was studied using a smaller stack data set with measurements of all four CTBT-relevant radioxenon isotopes. An increased frequency of detectable ${ }^{133 m} \mathrm{Xe} /{ }^{133} \mathrm{Xe}$ ratios is observed at shutdown, and the ratios agree well with a simulation of the reactor sequence in a three-isotope plot of the same type used to discriminate between nuclear tests and other sources.

Using SRS-fields provided by the IDC it is possible to show that atmospheric measurements in Stockholm are clearly impacted by the releases from the nuclear power plant. The isotopic ratios of the Stockholm measurements agree well with stack measurements, and with a modelled reactor operational sequence. However, the measured ${ }^{133 m} \mathrm{Xe} /$ ${ }^{133} \mathrm{Xe}$ ratios are on the average higher than expected, and the reason for this remains to be fully explained.

A mesoscale forward atmospheric dispersion calculation, using the stack measurements as input, was used to model the measurements of ${ }^{133} \mathrm{Xe}$ in Stockholm. The arrival times and plume widths agree very well with the observations, however, the modelled absolute activity concentrations were occasionally found to under-predict the measurements.

The results illustrates the importance of having detailed knowledge of radioxenon emissions from nuclear power plants in work related to nuclear test verification, and provide new input to this kind of analysis. Furthermore, it demonstrates the possibility to use sensitive radioxenon detection systems to detect and verify reactor operation at mesoscale distances.

We finally note that the Forsmark release and the SAUNA measurement series are unique since they have a closely specified source term and well resolved downstream measurements for a very long duration. It would be difficult to design and conduct a corresponding field trial. Hence this data set is very valuable for dispersion model development or dispersion model validation.

\section{Acknowledgements}

Open access funding provided by Swedish Defence Research Agency. The funding has been received from Utrikesdepartementet.

Open Access This article is licensed under a Creative Commons Attribution 4.0 International License, which permits use, sharing, adaptation, distribution and reproduction in any medium or format, as long as you give appropriate credit to the original author(s) and the source, provide a link to the Creative Commons licence, and indicate if changes were made. The images or other third party material in this article are included in the article's Creative Commons licence, unless indicated otherwise in a credit line to the material. If material is not included in the article's Creative Commons licence and your intended use is not permitted by statutory regulation or exceeds the permitted use, you will need to obtain permission directly from the copyright holder. To view a copy of this licence, visit http://creativecommons.org/licenses/by/4. $0 /$.

Publisher's Note Springer Nature remains neutral with regard to jurisdictional claims in published maps and institutional affiliations.

\section{REFERENCES}

Achim, P., Generoso, S., Morin, M., Gross, P., Le Petit, G., \& Moulin, C. (2016). Characterization of Xe-133 global atmospheric background: Implications for the international monitoring system of the comprehensive nuclear-test-Ban Treaty. Journal of Geophysical Research: Atmospheres, 121(9), 4951-4966. https://doi.org/10.1002/2016JD024872.

Axelsson, A., \& Ringbom, A. (2003). Xenon air activity concentration analysis from coincidence data. FOI report FOI-R-0913SE.

Björnham, O., Grahn, H., von Schoenberg, P., Liljedahl, B., Waleij, A., \& Brännström, N. (2017). The 2016 Al-Mishraq sulphur plant fire: Source and health risk area estimation. Atmospheric Environment, 169, 287-296. https://doi.org/10.1016/j.atmosenv.2017. 09.025.

Broed, R., Rensfeldt, V., Grusell, E., Häggkvist, K., Alpfjord, H., \& Fermvik, A. (2017). PREDO - PREdiction of DOses from normal releases of radionuclides in the environment - Site report Forsmark. Vattenfall Report,. QP.50000-63747892.

CTBTO (2019) Website of the Preparatory Commission for the Comprehensive Nuclear-Test-Ban Treaty Organization. http:// www.ctbto.org/. Accessed 15 Sept 2019.

De Geer, L. E. (2007). The Xenon NCC method revisited. FOI report FOI-R-2350-SE.

Eslinger, P., Biegalski, S., Bowyer, T., Cooper, M., Haas, D., Hayes, J., et al. (2014). Source term estimation of radioxenon released from the Fukushima Dai-ichi nuclear reactors using measured air concentrations and atmospheric transport modeling. 
Journal of Environmental Radioactivity, 127, 127-132. https:// doi.org/10.1016/j.jenvrad.2013.10.013.

Fritioff, T., Axelsson, A., Mörtsell, A., \& Ringbom, A. (2017). SAUNA III new beta detector. Science and Technology 2017 Conference, Vienna, Austria (poster), https://ctnw.ctbto.org/ DMZ/abstract/21821. Accessed 15 Sept 2019.

Grahn, H., von Schoenberg, P., \& Brännström, N. (2015). What's that smell? Hydrogen sulphide transport from Bardarbunga to Scandinavia. Journal of Volcanology and Geothermal Research, 303, 187-192. https://doi.org/10.1016/j.jvolgeores.2015.07.006.

Hoffman, I., \& Berg, R. (2018). Medical isotope production, research reactors and their contribution to the global xenon background. Journal of Radioanalytical and Nuclear Chemistry, 318(1), 165-173. https://doi.org/10.1007/s10967-018-6128-2.

Kalinowski, M. B., \& Tuma, M. P. (2009). Global radioxenon emission inventory based on nuclear power reactor reports. Journal of Environmental Radioactivity, 100(1), 58-70. https:// doi.org/10.1016/j.jenvrad.2008.10.015.

Kalinowski, M. B., Axelsson, A., Bean, M., Blanchard, X., Bowyer, T. W., Brachet, G., et al. (2010). Discrimination of nuclear explosions against civilian sources based on atmospheric xenon isotopic activity ratios. Pure and Applied Geophysics, 167(4), 517-539. https://doi.org/10.1007/s00024-009-0032-1.

Lewis, B., Chan, P., El-Jaby, A., Iglesias, F., \& Fitchett, A. (2017). Fission product release modelling for application of fuel-failure monitoring and detection-an overview. Journal of Nuclear Materials, 489, 64-83. https://doi.org/10.1016/j.jnucmat.2017. 03.037.

Rearden, B T., \& Jessee, MA. Eds (2016). Scale code system. ORNL/TM-2005/39, Version 62, Oak Ridge National Laboratory, Oak Ridge, Tennessee Available from Radiation Safety Information Computational Center as CCC-834.

Ringbom, A., Larson, T., Axelsson, A., Elmgren, K., \& Johansson, C. (2003). SAUNA-a system for automatic sampling, processing, and analysis of radioactive xenon. Nuclear Instruments and Methods in Physics Research Section A: Accelerators, Spectrometers, Detectors and Associated Equipment, 508(3), 542-553. https://doi.org/10.1016/S0168-9002(03)01657-7.

Ringbom, A., Aldener, M., Axelsson, A., Fritioff, T., Kastlander, J., Mörtsell, A., \& Olsson, H. (2017). Analysis of data from an intercomparison between a SAUNA II and a SAUNA III system. Science and Technology 2017 Conference, Vienna, Austria (poster), https://ctnw.ctbto.org/DMZ/abstract/21838. Accessed 15 Sept 2019.

Saey, P. R., Bowyer, T. W., \& Ringbom, A. (2010). Isotopic noble gas signatures released from medical isotope production facilities-simulations and measurements. Applied Radiation and Isotopes, 68(9), 1846-1854. https://doi.org/10.1016/j.apradiso. 2010.04.014.

Saey, P. R. J., Ringbom, A., Bowyer, T. W., Zähringer, M., Auer, M., Faanhof, A., et al. (2013). Worldwide measurements of radioxenon background near isotope production facilities, a nuclear power plant and at remote sites: The "EU/JA-II" Project. Journal of Radioanalytical and Nuclear Chemistry, 296(2), 1133-1142. https://doi.org/10.1007/s10967-012-2025-2.

Sato, Y., Takigawa, M., Sekiyama, T. T., Kajino, M., Terada, H., Nagai, H., et al. (2018). Model Intercomparison of Atmospheric 137Cs From the Fukushima Daiichi Nuclear Power Plant Accident: Simulations Based on Identical Input Data. Journal of Geophysical Research: Atmospheres, 123(20), 11748-11765. https://doi.org/10.1029/2018JD029144.

Wotawa, G., De Geer, L. E., Denier, P., Kalinowski, M., Toivonen, H., D'Amours, R., et al. (2003). Atmospheric transport modelling in support of CTBT verification-overview and basic concepts. Atmospheric Environment, 37(18), 2529-2537. https://doi.org/ $10.1016 /$ S1352-2310(03)00154-7. 